\title{
Role of School Meal Service in Nutrition
}

\author{
Hiromi ISHIDA \\ Kagawa Nutrition University, Sakado 350-0288, Japan
}

\begin{abstract}
Summary School meal service programs are essential for children's long-term nutrition and health promotion. The programs vary in content, depending on the economic condition, health condition and the food supply situation in each country. Children are encouraged to improve their nutrition, and choose healthy foods and learn good dietary habits through school meals and nutrition education. In Japan, the school lunch program started in 1889. The percentage of elementary schools serving school lunches had reached $99.2 \%$ in 2014 , and the Nutrition Teacher system started in 2004. Nutrition teachers are to play the roles of teachers on food and nutrition education in addition to managers of foodservice operations in schools. Nutrition teachers are expected to have effects on school nutrition programs by providing meal service together with nutrition education. And so, significant effort is needed from both academia and the field to raise the related nutritional issues.
\end{abstract}

Key Words school meal service, food and nutrition education, nutrition teacher

School meal service programs are initiated and promoted in various countries to help contribute to the healthy mental and physical development of children; these programs are effective methods of implementing nutritional policy for public health benefit. Food is continually supplied to children at school to improve their nutrition and well-being. The programs vary in content, depending on the economic condition, health condition (especially pediatric health) and the food supply situation in each country. The in-school program predominantly provides lunch; however, the service is not limited to lunch provisions, but is diverse, with offerings ranging from breakfast or dinner to take-home food packages (1-4). There are also countries that do not have school meal service programs but do provide milk to recipients (5). School meal service programs have taken advantage of their educational foundation to implement programs for nutritional improvement, which influences pediatric health conditions and reflects the significant social basis of program initiation in developing countries.

\section{History of School Lunch Program in Japan (6)}

School lunch programs started in Japan in 1889, when a private elementary school provided children of poor families with free meals in Yamagata Prefecture. A national institution in 1932, school lunch began to provide relief to children from impoverished families. In 1940, an aid project was undertaken for all children at school to improve nutritional conditions and physique. LARA (Licensed Agencies for Relief in Asia, a U.S. nongovernmental organization) relief supplies sent to Japan encouraged the spread of the school lunch, which alleviated malnourishment in 1946, after World War II, a time when food supplies were limited. By the year 1948, $61 \%$ of elementary schools provided school lunch. At that point, 10-y-old boys averaged $126.1 \mathrm{~cm}$ in height

E-mail: ishida@eiyo.ac.jp and $26 \mathrm{~kg}$ in weight; girls of the same age averaged $125.7 \mathrm{~cm}$ in height and $25.6 \mathrm{~kg}$ in weight. It was not long before the School Lunch Law was enacted in 1954 to establish a legal base to define the objectives, goals, and implementation of school lunch programs (7). Moreover, school lunch programs were provided at 99\% of elementary schools in 1975, when average measurements of height and weight were $136.4 \mathrm{~cm}$ and $31.5 \mathrm{~kg}$ for 10-y-old boys, respectively, and $137.6 \mathrm{~cm}$ and $32 \mathrm{~kg}$ for girls of the same age, respectively (8). As the number of schools participating in the school lunch program increased, so did the overall height and weight for children. This trend was recognized to be an effect of the implemented school lunch. However, around the year 2000, height reached a plateau and weight began to show a decline. A total of 6.76 million children were provided with school lunch at $99.2 \%$ of elementary schools in 2014 (9), at which point 10-y-old boys had an average height of $138.9 \mathrm{~cm}$ and average weight of $34 \mathrm{~kg}$ and 10-y-old girls had an average height of $140.1 \mathrm{~cm}$ and average weight of $34 \mathrm{~kg}(10)$. In addition, the school lunch was provided for 2.55 million children at $85.4 \%$ of middle schools in the same year (9).

\section{Nutritional Standards for School Meal Service}

The physical condition of children, including their intake of energy, nutrients, and food, is assessed to properly implement the school meal service; the program standards are established on the basis of the assessment results. In the U.K. and Korea, standards are set at one third of the daily nutritional requirements for boys and girls, separately $(4,11)$. Japan adopts one third of recommended dietary allowance (RDA) of Dietary Reference Intakes for Japanese in principle, but sets the standard at more than one third for nutrients that tend to be inadequately accounted for through intake (12). Established school lunch standards in Japan are at a level to be able to provide $40 \%$ of RDA of vitamins $A, B_{1}$, and $B_{2}$, and $50 \%$ of RDA calcium. The Japanese school system 
divides elementary school children into three groups by age (6-7, 8-9, and 10-11 y old) and puts middle school children in one group (12-14 y of age). However, its school lunch does not set separate nutritional standards for boys and girls. Food composition and meal patterns are also standardized to meet nutritional standards and to make up a meal, respectively in each country. Compositions of food items and cuisine lead to solutions for nutritional issues and, in addition, reflect food culture or food production so that meals possess value as teaching material for nutritional education. The composition of food is closely related not only to issues of nutrition, but also to those relating to food supply. After World War II, Japan was provided wheat flour and skimmed milk powder for the school meal service by the United Nations Children's Fund (UNICEF), and promoted school lunch that included bread. For the purpose of contributing to the concurrent development of local dairy farming, locally produced skimmed milk powder (and later, liquid milk) was supplied to the school meal service. In 1964, milk began to be supplied to the school lunch on a large scale, which influenced meal patterns of the program to a great extent. The school lunch program in Japan provides three types of meals. The first type consists of combinations of a staple food (shushoku: steamed rice, bread, or noodles), main dishes and/or side dishes (okazu), and milk. These are referred to as complete school meals. The second type is a supplementary meal. It is made up of okazu and milk. The third type is milk alone. A marked characteristic of all three meal types is the presence of milk, which is served in all meals. As for staples, meals with bread began to be promoted in order to correct nutritional deficits resulting from the overemphasis on rice in the diet, and to rationally improve the diet in 1954 (6). Rice was approved for use for school lunches in 1962 to effectively utilize locally produced food materials, promote their use, and make the school lunch more widespread (6). One issue was that wheat imported from the U.S. at the time was fortified with vitamins $\mathrm{B}_{1}$ and $B_{2}$. Because polished rice would be deficient in vitamins $\mathrm{B}_{1}$ and $\mathrm{B}_{2}$ compared with bread in the school meal service, rice enriched with these nutrients (fortified rice) was added to ordinary rice as a supplement. Because rice has a high food self-sufficiency ratio, this further popularized and established school meals with steamed rice as a staple. Rice-based meals were served at schools 3.3 times a week on average in 2013 (13).

\section{Verification of School Meal Service as a Dietary Intervention}

To verify the role of the school meal service in nutrition, surveys are conducted regarding the influence of school meal intake on daily intake of energy, nutrients, and specific food groups. For instance, in the U.K., where use of the school meal service is optional, cross-sectional surveys are conducted to compare the daily intake of children who bring lunch from home with that of those who use the school meal service (3). In addition, many studies have been carried out to assess whether active dietary intervention improves fruit and vegetable intake at schools (14). Randomized controlled trials are also performed to verify differences in daily intake between instances when healthy meals are provided by school meal service and when lunch is brought from home (5). Comparing lunch alone, the school meal service is clearly superior in nutrition to a meal brought from home, the reason being that the school meal service reflects the guidelines of relevant nutritional policies. In most cases, however, the school meal service often provides one meal a day, and intervenes on days when schools are open. Therefore, the influence of the school meal service on habitual intake is not as prevalent. The extent of its influence naturally depends on how school meals are related to other meals. In many cases, direct influence on physical conditions cannot be substantially confirmed, except in cases of restricted food supplies combined with observed nutritional deficiency. Japan is in a situation in which children attending school show little change in physique and the influence of the school meal service is difficult to confirm. Another reason for this is that a large number of schools provide the school meal service, making it difficult to verify differences in the service's effects between schools that serve school meals and those that do not. Therefore, studies only proceed as far as to compare energy and nutrient intake on days when school meals are served, and general intake on days when they are not (15). Nozue et al. examined the nutritional significance of milk served by the school meal service and that of the addition of vitamin $\mathrm{B}_{1}$-fortified rice; they revealed that the school meal service contributes to a reduction in the prevalence of these nutrient deficiencies among children (16).

\section{School Meal Service and Nutrition Education}

School meal services provide children with many opportunities to receive healthy, balanced meals. Such a dietary experience is repeated to give them several opportunities to change their dietary behavior. Therefore, the expected significance of the school meal service is to provide children with a basis for food and nutrition education, which covers a wide range of topics. It not only aims to form desirable eating habits, but also strengthens children's understanding of food production, transportation, and food culture, as well as an appreciation of the gift of nature that support us, and the people who provide the school meal service. Both Japan and Korea have made this field of food and nutrition education an institution. The nutrition teacher system was implemented in Japan in 2004 and in Korea in 2006 (4, 6), whereby a school dietician in charge of meal service management is able to acquire a teacher's certificate and may facilitate food and nutrition education as a teacher. And so, nutrition teachers are expected to have effects on school nutrition programs by providing meal service together with nutrition education. In Japan, the number of teachers using this program increased from 34 in 2005 to 5,023 in 2014 (17), a number comprising about $40 \%$ of all nutrition experts placed at schools. Future research will reveal the achievements and outcomes of the institution of nutrition teachers in both 
countries. Significant effort is needed from both academia and the field to raise the related nutritional issues.

\section{Future of School Meal Service Programs}

In some countries, fees for school meal services depend on family income; meals may be supplied free of charge, at a reduced charge, or at full charge. There are also countries where the use of the school meal service itself is optional. Efficient management of school meal service is very important. For instance, there is a conventional system by which each school prepares and serves meals, and a central kitchen system by which meals are prepared at one location and delivered to schools. There is also an increasingly popular trend in which some schools commission food service-specialized firms to manage school meal services or to prepare meals. Some schools pay close attention to cost-effectiveness and adopt a scratch-cooking system by which prepared food is procured to save labor and cooking time (18). It is a big issue to build and maintain a system that takes into consideration the health and nutritional wellbeing of children to provide high quality meals contributing to the formation of desirable dietary habits. In recent years, many nations have been facing a dual problem: nutritional deficiency and excess. A country may have a problem of food and nutrient intake as it relates to the health disparities, against a background of income and socioeconomic status disparities. Alternatively, an individual may face the problem of simultaneous nutritional deficiency and excess. In addition to addressing the nutritional problems of a population, nutritional issues of individual children (including obesity, underweight or food allergies) need to be addressed. The method by which we must sustain and develop a school meal service program should be considered while developing policies regarding nutrition for each country that implements such a program.

\section{REFERENCES}

1) U.S.Department of Agriculture. Nutrition Standards in the National School Lunch and School Breakfast Programs. http://www.gpo.gov/fdsys/pkg/FR 2012-01-26/ pdf/2012-1010.pdf [Accsesed December 1, 2014].

2) U.S.Department of Agriculture. National School Lunch Programs. http://www.ers.usda.gov/topics/food-nutrition-assistance/child-nutrition-programs/nationalschool-lunch-program.aspx. [Accsesed December 1, 2014].

3) Spence S, Delve J, Stamp E, Matthews JNS, White M, Adamson AJ. 2013. The impact of food and nutrientbased standards on primary school children's lunch and total dietary intake: A natural experimental evaluation of overnment policy in England. Plos one 8(10): 1-8.

4) Yoon J, Kwon S, Shim JE. 2012. Present status and issues of school nutrition programs in Korea. Asia Pac J Clin Nutr 21: 128-133.

5) Andersen R, Biltoft-Jensen A, Christensen T, Andersen EW, Ege M, Michaelsen KF, Tetens I. 2014. Dietary effects of introducing school meals based on the New Nordic Diet-a randomized controlled trial in Danish children. The OPUS School Meal Study. Br J Nutr 111:
1967-1976.

6) Federation of Prefectural School Lunch Association of Japan. The History of School Lunch Services. http:// warp.da.ndl.go.jp/info:ndlip/pid/239790/www.ntgk. go.jp/kyusyoku/history/hisinde x.html (in Japanese) [Accsesed December 5, 2014].

7) Ministry of Education, Culture, Sports, Science and Technology. 1954. School Lunch Law. Tokyo.

8) Ministry of Education, Culture, Sports, Science and Tecnology. 2005. School health statistics (in Japanese). http://www.mext.go.jp/b-menu/tokei/001/003/ 17/06030312/002.htm [Accsesed December 5, 2014].

9) Ministry of Education, Culture, Sports, Science and Tecnology. 2012 School lunch implementation status (in Japanese). http://www.mext.go.jp/b-menu/tokei/ chousa05/kyuushoku/kekka/k-detail/_icsFiles/afieldfile/2014/01/23/1343511_3.pdf [Accsesed December $5,2014]$.

10) Ministry of Education, Culture, Sports, Science and Tecnology. 2013 School health statistics (in Japanese). http://www.mext.go.jp/component/b_menu/other/_ icsFiles/afieldfile/2014/04/04/1314157_3.pdf [Accsesed December 5, 2014].

11) School Food Trust: A Guide to introducing the Government's food-based and nutrient-based standards for school lunches. www.childrensfoodtrust.org.uk/ resources/guide-to-the-nutrient-based-standards [Accsesed December 5, 2014].

12) Study collaborators Conference on Dietary Reference Intakes development of students in the school meal. 2011. For the development of school meal reference intakes (Report), Tokyo, (in Japanese).

13) Ministry of Education, Culture, Sports, Science and Tecnology. 2013 School lunch implementation status (in Japanese). http://www.mext.go.jp/b-menu/tokei/ chousa05/kyuushoku/kekka/k-detail/_icsFiles/afieldfile/2014/01/23/1343511_3.pdf [Accsesed December 5, 2014].

14) Evans CEL, Christian MS, Cleghorn CL, Greenwood DC, Cade JE. 2012. Systematic review and meta-analysis of school-based interventions to improve daily fruit and vegetable intake in children aged 5 to 12 y. Am J ClinNutr 96: 889-901.

15) Nozue M, Jun K, Ishihara Y, Taketa $Y$, Nagai N, Yoshita K, Ishida H. 2010. Differences in food consumption and distribution of meals between the days with or without school lunches among 5 th grade elementary school students. Jpn J Nutr Diet 68: 298-308.

16) Nozue M, Jun K, Ishihara $Y$, Taketa $Y$, Nruse A, Nagai N, Yoshita K, Ishida H. 2013. How does fortification affect the distribution of calcium and vitamin $\mathrm{B}_{1}$ intake at the school lunch for fifth-grade children? J Nutr Sci Vitaminol 59: 22-28.

17) Ministry of Education, Culture, Sports, Science and Tecnology. 2014. The number of Nutrition teaches (in Japanese). http://www.mext.go.jp/a_menu/sports/ syokuiku/08040314.htm [Accsesed December 5, 2014].

18) Woodward-Lopez G, Kao J, Kiesel K, Miller ML, Boyle M, Drago-Ferguson S, Braff-Guajardo E, Crawford P. 2014. Is scratch-cooking a cost-effective way to prepare healthy school meals with US Department of Agriculture Food? J Acad Nutri Diet 114(9): 1349-1358. 